\title{
Ultrastructure and Immunolocalization of Transforming Growth Factor-Beta in Chondrification of Murine Ligamentous Fibroblasts and Endochondral Calcification Induced by Recombinant Human Bone Morphogenetic Protein-2
}

\author{
Kazuto Hoshi ${ }^{1,2}$, Norio Amizuka ${ }^{1}$, Takahide Kurokawa ${ }^{2}$ and Hidehiro Ozawa ${ }^{1}$ \\ ${ }^{1}$ First Department of Oral Anatomy, Niigata University School of Dentistry, 5274, 2-Bancho, Gakkocho-dori, Niigata, \\ 951 and ${ }^{2}$ Department of Orthopaedic Surgery, Faculty of Medicine, The University of Tokyo, 7-3-1, Hongo, \\ Bunkyo-ku, Tokyo, 113
}

Received for publication July 3, 1997 and revised form August 1, 1997

\begin{abstract}
In order to elucidate the causes of ossification in spinal ligaments, ultrastructural alteration and immunolocalization of transforming growth factor- $\beta$ (TGF- $\beta$ ), as well as that of the TGF- $\beta$ receptor were examined during the chondrification of ligamentous fibroblasts, by inducing ossification in ligamenta flava of murine lumbar spines, employing recombinant human bone morphogenetic protein-2 (rhBMP-2). Normal ligamenta flava, consisting of flattened fibroblasts, showed no immunolocalization of TGF- $\beta$ isoforms. From the second week following BMP-administration, cartilage gradually replaced the ligaments. Cells in the central portion of the ligament contained abundant Golgi apparatus as well as enlarged endoplasmic

reticula. Proliferative or hypertrophic chondrocytes in this area showed immunoreactivity to TGF- $\beta_{3}$ latency-associated peptide, while calcified hypertrophic chondrocytes accompanied by both matrix vesicle- and collagen-calcification were noticed at the insertion site to spinal lamina, where there was no immunolocalization of this peptide. In addition, the TGF- $\beta$ type I receptor was localized on the proliferative and hypertrophic cells of the central portion. Therefore, as regards the pathological chondrification of ligamentous fibroblasts induced by exogenous BMP2 , TGF- $\beta$ is speculated to promote matrix-formation and chondrocytic maturation, under the autocrine/paracrine system, in concert with exogenous BMP-2.
\end{abstract}

Key words: Ossification of spinal ligaments, Bone morphogenetic protein, Transforming growth factor-beta, Immunohistochemistry, Fine structure

\section{Introduction}

Ossification of spinal ligaments, including that which occurs in the posterior longitudinal ligament or the ligamentum flavum, inevitably leads to spinal cord compression and severe paralysis. Although this disease is the principal cause of myelopathy, its pathology is unclear. Our experimental model therefore attempts to elucidate the process by which ossification of spinal ligaments is induced by recombinant human bone morphogenetic protein-2 (rhBMP-2), as established by the authors [8]. The

Selected by "The 10th International Congress of Histochemistry and Cytochemistry" held in Kyoto, Japan on Aug. 18-23, 1996.

Correspondence to: Kazuto Hoshi, M.D., First Department of Oral Anatomy, Niigata University School of Dentistry, 5274, 2-Bancho, Gakkocho-dori, Niigata, 951, Japan. ossification process in this instance is similar to that observed in clinica, as shown by; 1) the fact that it commenced at the insertion site of ligament to bone; 2) that it advanced endochondrally. It is therefore quite useful in analyzing morphological changes during bone formation. Our experimental model indicated that the chondrification of ligamentous fibroblasts occurred at the initial phase of ossification, and that BMPs would play an important role, since the BMP receptors were up-regulated during the pathological process . In the present study, the character of BMP-induced cartilage and its calcification were examined ultrastructurally in order to gain insight into the pathway that leads to the chondrification of ligamentous fibroblasts.

Earlier clinico-pathological data obtained during immunohistochemical studies of ossification of spinal ligametns documented the presence of BMP-2 and 
transforming growth factor- $\beta$ (TGF- $\beta$ ) [11]. Their findings further suggested a relationship between the TGF$\beta$ superfamily and this condition. TGF- $\beta$ enhances bone formation, when injected into the periosteum $[9,13,19]$. Unlike BMP-2, however it does not induce ectopic osteogenesis, by either intramuscular or subcutaneous implantation. TGF- $\beta$ 's role in ossification of spinal ligaments remains ill-defined. We therefore conducted immunohistochemical analyses of this cytokine and its receptor.

\section{Materials and Methods}

\section{Tissue preparation}

In order to induce the ossification of spinal ligaments, rhBMP-2 solution $(40 \mu \mathrm{g} / 100 \mu \mathrm{l})$ was injected around the area of ligamenta flava in lumbar spines of 12-week-old male ddY mice (Nihon SLC, Hamamatsu, Japan) according to the method described previously [8].

At the second week following BMP-2 injection, after anesthesia with inhalation of diethyl ether and intraabdominal administration of sodium pentobarbiturate, the mice were perfused with $50 \mathrm{ml}$ of $4 \%$ paraformaldehyde in $0.1 \mathrm{M}$ cacodylate buffer $(\mathrm{pH} 7.4)$ or a mixture of $2 \%$ paraformaldehyde and $2.5 \%$ glutaraldehyde in $0.067 \mathrm{M}$ cacodylate buffer ( $\mathrm{pH}$ 7.4) for paraffin embedding and frozen section, or epoxy resin embedding, respectively. Ligamenta flava administered with BMP-2 were removed en bloc with surrounding tissues such as spines, spinal cord, and paravertebral muscles, and immersed in the fixative same as above for $2 \mathrm{hr}$ at $4^{\circ} \mathrm{C}$. The specimens were decalcified with $10 \%$ EDTA or $4.13 \%$ EDTA at $4^{\circ} \mathrm{C}$ for paraffin and frozen sections, or epoxy resin embedding, respectively. After decalcification with 10\% EDTA, some specimens were dehydrated with an increasing concentration of ethanol and embedded in paraffin, others were immersed in PBS containing sucrose of which concentration was ascended gradually to $10 \%, 20 \%$, and $25 \%$, and then, were rapidly frozen in liquid nitrogen. For epoxy resin embedding, the specimens were embedded in $7 \%$ agar and sliced at the thickness of $200 \mu \mathrm{m}$ using Microslicer DTK1000 (DSK, Kyoto, Japan). Following postfixation with

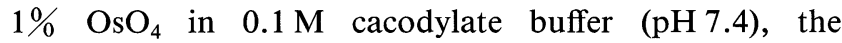
specimens were dehydrated in a graded acetone series, and embedded in Poly/Bed 812 resin (Polysciences, Inc., Warrington, PA).

Three groups of mice were compared; one treated with BMP-2, one in which the solution lacked the protein, and the last, given no treatment, whatsoever.

\section{Histology and fine structure}

Five $\mu \mathrm{m}$-thick continuous paraffin sections were stained with Azan for light microscopy.

Ultrathin sections of Poly/Bed-embedding specimens were obtained using Porter-Blum MT-II ultramicrotome (Sorvall, Newtown, CT). For observation of calcified components, ultrathin sections of undecalcified samples were collected on ethylene glycol. The ultrathin sections were stained with tannic acid, uranyl acetate, and lead citrate and observed under a transmission electron microscope (TEM) JEM-100CX II (JOEL Ltd., Tokyo, Japan).

\section{Immunohistochemistry}

In immunohistochemical tests for TGF- $\beta$, the dewaxed paraffin sections were treated with $0.3 \%$ hydrogen peroxide in PBS, for $30 \mathrm{~min}$, at room temperature. After blocking by PBS containing 10\% bovine serum albumin (10\% BSA-PBS, Seikagaku, Tokyo, Japan) for $2 \mathrm{hr}$, at room temperature, they were incubated in a polyclonal rabbit antisera for TGF- $\beta_{1}$ latency-associated peptide (LAP), $-\beta_{2}$ LAP, $-\beta_{3}$ LAP (A96, A94, A95, dilution ratio $1: 200$ ) at $4^{\circ} \mathrm{C}$ for $12 \mathrm{hr}[14,18]$. The sections were rinsed in PBS, and incubated with horseradish peroxidase (HRP)-conjugated anti-rabbit IgGs antibody $(1: 200)$ for $1 \mathrm{hr}$ at room temperature. After washing with PBS, the sections were immersed in a diaminobenzidine (DAB) solution for $5 \mathrm{~min}$ at room temperature.

For immunostaining against the TGF- $\beta$ receptor, frozen $8 \mu \mathrm{m}$ sections obtained by Minotome (Damon, Needham, MA) were treated with $0.3 \%$ hydrogen peroxide in PBS for $30 \mathrm{~min}$ at room temperature. After blocking by $10 \%$ BSA-PBS for $2 \mathrm{hr}$ at room temperature, they were incubated with polyclonal rabbit antisera against the TGF$\beta$ type I receptor $(1: 100)$ for $24 \mathrm{hr}$ at $4^{\circ} \mathrm{C}[5,15]$. After washing with PBS, the sections were immersed with biotinylated anti-rabbit IgGs antibody (Nichirei, Tokyo, Japan) for $30 \mathrm{~min}$ at room temperature, peroxidase conjugated streptavidin (Nichirei) for $30 \mathrm{~min}$ at room temperature, and a DAB solution for $5 \mathrm{~min}$ at room temperature.

As a negative control, non-immune rabbit serum at the same dilution was used instead of the primary antisera.

\section{Results}

\section{Morphological alteration of ligamenta flava following BMP-injection}

Normally, ligamentum flavum containing an abundance of fibrous tissue interconnects the cranial and caudal spinal laminae (Fig. 1A). From the second week following BMP-injection, ligamentous tissue had been completely replaced by cartilage (Fig. 1B). Several thick, fibrous bundles were noted in the central portion of the cartilaginous matrix, an image not unlike that of fibrous cartilage. At the site where it unites to spinal lamina, considerable vascular invasions were observed. The control group, by contrast, showed no specific changes, such as cartilage formation, in the ligaments, when deprived of BMP-2. These findings mirrored those of the untreated group.

Viewed TEM, ligamentous fibroblasts, including their nuclei, were flattened. They were surrounded by a dense concentration of thick collagen fibrils, $30-60 \mathrm{~nm}$ in diameter (Fig. 2A). At the second week after injection of 

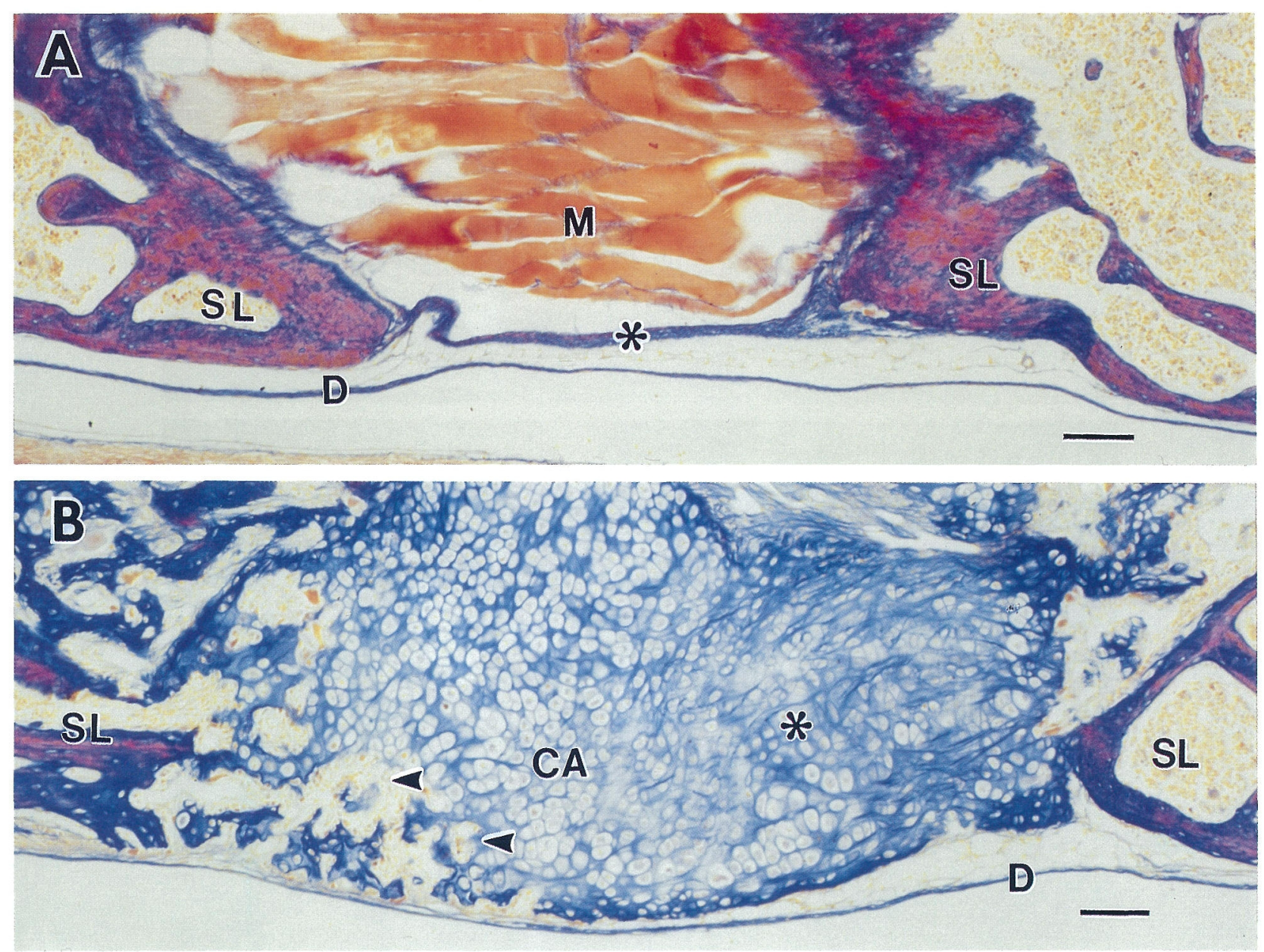

Fig. 1. Histological findings in Azan staining. A: No treatment. Normal ligamentum flavum (*) is stained deep blue, because of the abundance of fibrous elements. B: The second week following BMP-injection. Ligamentous tissue has been completely replaced by cartilage (CA). In the vicinity of the insertion site, vascular invasion is noted (arrowheads). In some areas of the cartilagenous tissue, deeply stained fibrous bundles are observed $(*)$. SL : spinal lamina, M: muscle, D: dura mater of spinal cord. Original magnification $=\times 96$, bars $=100 \mu \mathrm{m}$.

BMP-2, oval chondrocytes with round nuclei were observed in the central portion. These were surrounded by a commingling of both thick collagen fibrils, and thin ones from a few to $20 \mathrm{~nm}$ in diameter (Fig. 2B). In this instance, rough endoplasmic reticula (ER) were enlarged, while many Golgi apparatus were noted, all of which resembled findings for proliferative chondrocytes, or those which had hypertrophied (Fig. 2C).

In the insertion site, extracelluar portions deeply stained by toluidine were noted around the chondrocytes, near the sites of vascular invasion. These were regarded to be areas of calcification (Fig. 3A). These chondrocytes resembled hypertrophic cells in hyaline cartilage, being surrounded as they were by thin collagen fibrils, confined in cartilage lacunae, and possessing low electron-density cytoplasms (Fig. 3B). The extracellular matrices of some were marked by scattered thick collagen fibrils, or specific lacuna which occupied a complicated network loosely interwoven of both thick collagen fibrils and proteoglycan granules (Fig. 3-C, D). Areas of endochondral calcification surrounded hypertrophic cells. Matrix vesicles, from 30 to hundreds of nanometers in diameter, containing needle-like crystals, or calcified collagen were present in the calcified areas (Fig. 4-A, B, C).

\section{Immunolocalizations of TGF- $\beta$ and its receptor in BMP- induced cartilage}

Neither TGF- $\beta_{1}$ LAP, nor $-\beta_{2}$ LAP showed specific immunolocalizations, in either ligamentous or cartilaginous tissues. Flattened fibroblasts in normal ligaments demonstrated little tendency toward immunopositivity for TGF$\beta_{3}$ LAP (Fig. 5A). However, in the second week following BMP-injection, immunolocalization for TGF- $\beta_{3}$ LAP was seen in the proliferative and hypertrophic chondrocytes of the central portion, although the hypertrophic cells near the vascular invasion in the insertion site showed none whatsoever (Fig. 5B). The TGF- $\beta$ type I receptor was also detected in proliferative and hypertrophic chondrocytes 

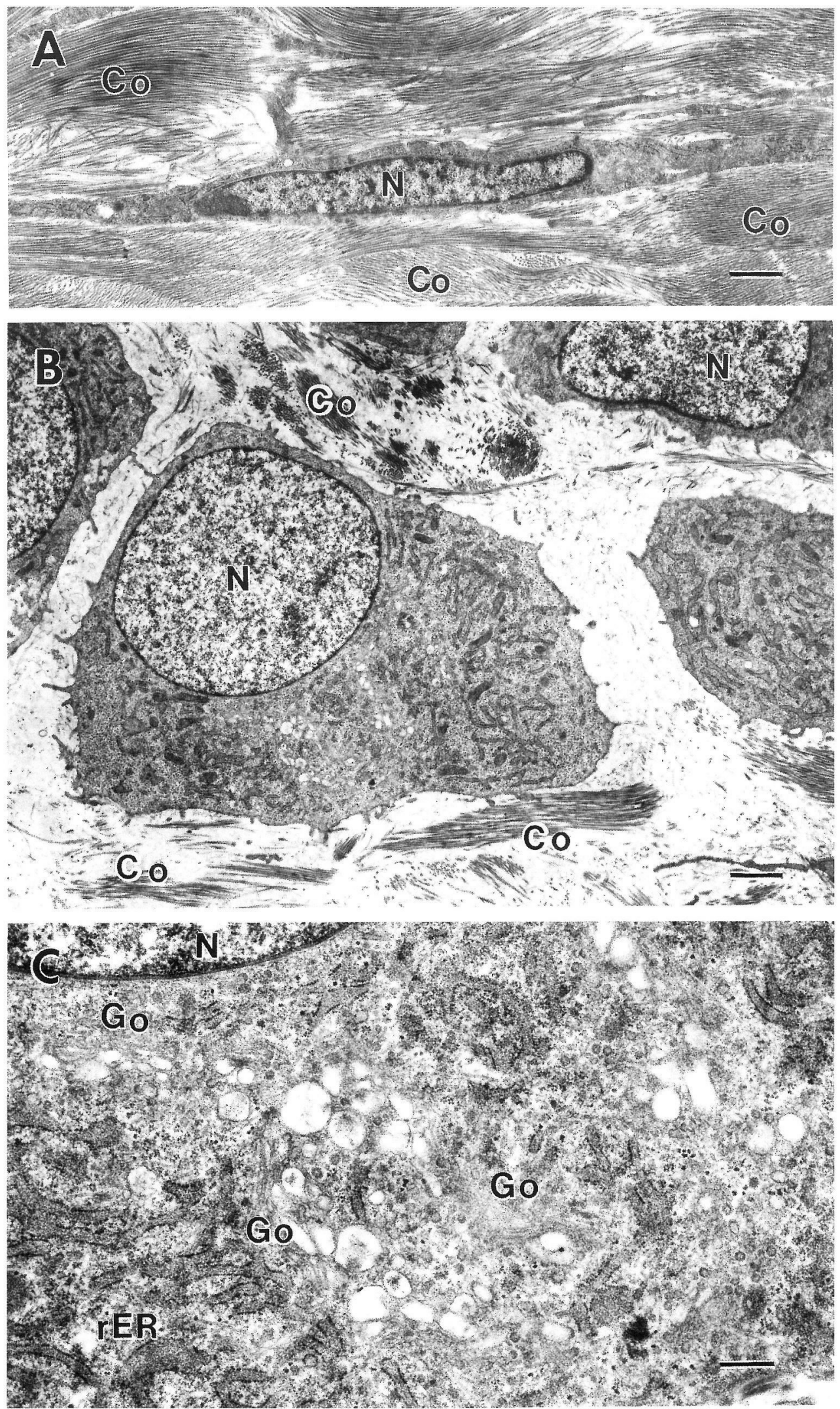

Fig. 2 



Fig. 3. Chondrocytes around the area of vascular invasion at the second week following BMP-injection. A: Light microgram of an undecalcified section stained in toluidine blue. Some extracellular areas (arrowheads) were stained deeply, suggesting possible calcification. Original magnification $=\times 1000$, bar $=10 \mu \mathrm{m} . \mathbf{B}, \mathbf{C}, \mathbf{D}$ : Electron micrograms of decalcified sections. B: A hypertrophic chondrocyte surrounded by cartilage lacuna (arrowhead), containing cytoplasms of low electron density. Original magnification $=\times 3000$, bar $=3 \mu \mathrm{m}$. $\mathbb{C}$, D: In the lacuna of another hypertrophic chondrocyte, loosely interwoven thick fibrils of collagen formed a network in concert with proteoglycan granules. D: magnification of $(*)$ in C. C: Original magnification $=\times 4800$, bar $=3 \mu \mathrm{m}$. D: Original magnification $=\times 33000$, bar $=0.25 \mu \mathrm{m}$.

Fig. 2. Ultrastructural alteration of ligamentous cells, following BMP-injection. A: No treatment. Flattened fibroblasts are surrounded by a dense concentration of thick collagen fibrils $(\mathrm{Co})$. Original magnification $=\times 8000, \mathrm{bar}=1 \mu \mathrm{m} . \mathbf{B}, \mathbf{C}:$ A chondrocyte in the central portion of the ligament, at the second week following BMP-injection. B: A chondrocyte is visible among thin collagen fibrils. Some areas of extracellular matrix contain thick collagen fibrils (Co). Original magnification $=\times 4000$, bar $=2 \mu \mathrm{m}$. C: Enlargement of rough ER (rER) and accumulation of Golgi apparatus (Go) are found intracellularly. Many Golgi vesicles are observed in the vicinity of Golgi apparatus. Original magnification $=\times 40000$, bar $=0.2 \mu \mathrm{m}$. N: nucleus. 

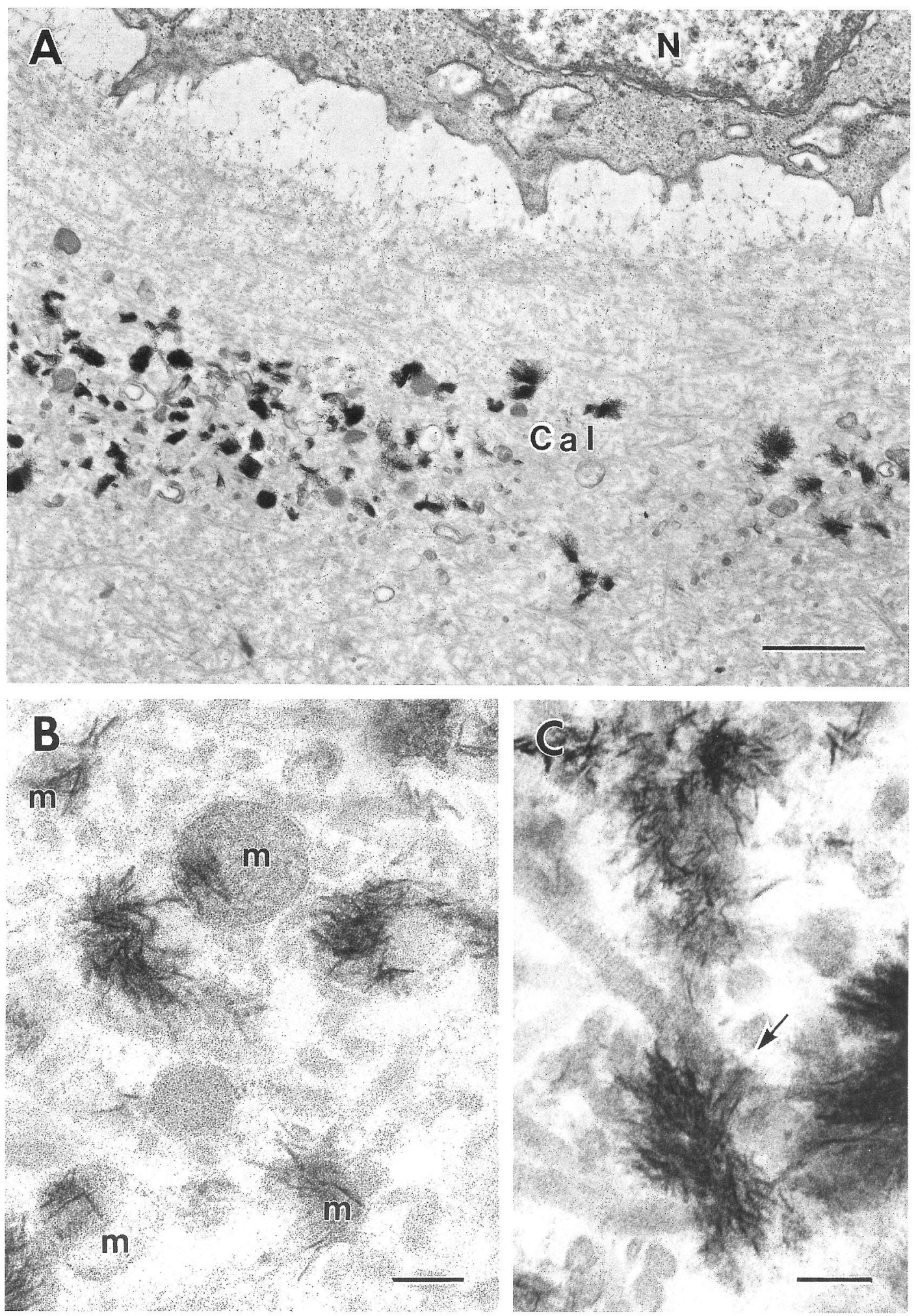

Fig. 4. Fine structure of endochondral calcification at the second week following BMP-injection. A: Calcification areas (Cal) are observed around chondrocytes in the vicinity of vascular invasion. Original magnification $=\times 16000$, bar $=1 \mu \mathrm{m}$. B, C: High magnifications of calcification area (Original magnification $=\times 125,0000$, bar $=10 \mathrm{~nm}$ ). Needle-like crystals are visible within matrix vesicles $(\mathrm{m})$. Collagen calcification (arrow) is also observed. 

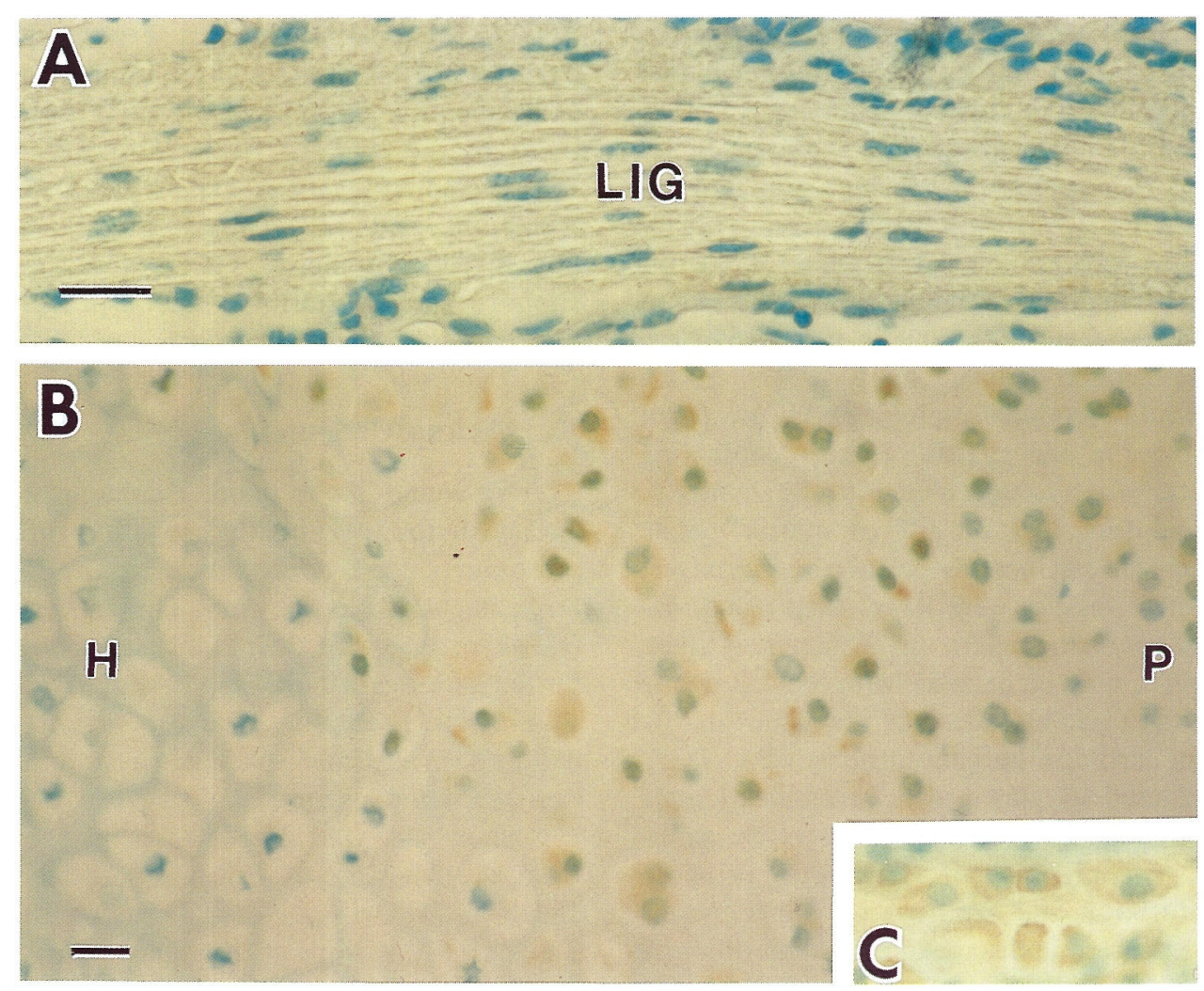

Fig. 5. Immunolocalizations of TGF- $\beta_{3}$ LAP and the TGF- $\beta$ type I receptor. A: No treatment. Immunostain for TGF- $\beta_{3}$ LAP. Flattened fibroblasts show no immunoreactivity. LIG : ligamentum flavum. B: The second week following BMP-injection. Immunostain for TGF- $\beta_{3}$ LAP. Proliferative and hypertrophic chondrocytes in the central portion $(\mathrm{P})$ show some immunolocalization, while no detectable signals are observed in hypertrophic chondrocytes at the insertion site $(\mathrm{H})$. $\mathbf{C}$ : The second week following BMP-injection. Immunostain for the TGF- $\beta$ type I receptor. It was detected in proliferative and hypertrophic chondrocytes of the central portion. A: Original magnification $=\times 500$, B, C: Original magnification $=\times 300$. Bars $=20 \mu \mathrm{m}$.

(Fig. 5C). Non-immune rabbit serum showed no immunoreactivity, when used in place of the specific antibodies.

\section{Discussion}

In the present study, rhBMP-2 were administered in a highly concentrated solution without any kinds of carriers, in order to avoid the inevitable invasion and damage to the fine structure of ligamentous tissue. The dosage of rhBMP-2 was chosen according to the previous report [8]. Atraumatic treatment of the ligamentous tissues by the application of injection method enabled us to observe the fine structure at the cellular level.

BMP-induced cartilage in the spinal ligaments possessed characteristics of both fibrous and hyaline cartilage. In the present experiment, the histological features observed following BMP-administration in the insertion site were different from those recognized in the central portion. While fibrous cartilage containing both thick and thin collagen fibrils was found in the central portion, the insertion site was mainly characterized by the presence of hyaline cartilage consisting of thin collagen fibrils. Thick and thin fibrils seemed to correspond to types I and II, respectively, because of their diameter. In the insertion site, vascular invasion followed by endochondral ossification were also noted. Therefore, the presence of fibrous cartilage may indicate a middle stage between a ligament and the formation of hyaline cartilage, during pathological differentiation.

Regarding the fine structures, the proliferative and hypertrophic chondrocytes in the central portion contained enlarged rough ER and accumulations of Golgi apparatus as well as Golgi vesicles. They seemed to synthesize and secrete a variety of substances, including collagen or proteoglycan. Some lacunae of hypertrophic chondrocytes in the insertion site contained structures consisting of networks of loosely interwoven thick collagen fibrils and granular forms of proteoglycan. This structure was found in BMP-induced cartilage, which seemed to suggest that it was an intermediate stage between fibrous and hyaline cartilage $[4,12]$. Moreover, this type of cell tends to have an extremely irregular contour, and endocytotic appearance. Since the rapid shift of type I collagen-rich matrix to that abundant with type II is nessecary during this period, these chondrocytes may actively participate in the resorption of the extracellular matrix, like fibroclasts. 
Although calcification, for the most part, occurred in the area of hyaline cartilage, the fibrous cartilage was also affected. As to specific type, matrix vesicle calcification was recognized in BMP-induced cartilage. These vesicles formed a scaffold in calcification, during endochondral ossification of growth plate or intramembraneous ossification of calvaria, as well as the calcification of fibrous cartilage [21]. Although the previous report seemed to indicate the presence of matrix vesicle in the area of the endochondral calcification induced by BMP [7], in the present study, ultrathin sections employing ethylene glycol enabled us to observe the matrix vesicles containing needle-like crytals, what is speculated to be hydroxyapatite, and to confirm that a shift of matrix vesicle calcification to collagen calcification occurred. Moreover, BMP-induced matrix vesicles were larger than usual, exceeding hundreds of nanometers in diameter. These larger matrix vesicles may be derived from the cell debris produced during the rapid alteration of the ligaments.

In this type of cartilage, immunolocalization of TGF$\beta$, which is speculated to play a role in ossification of spinal ligaments, as well as that of its receptor were examined. TGF- $\beta$ was generally thought to not only promote chondrocytic maturation and synthesis of proteoglycan, but also postpone the terminal stage of differentiation and calcification in the cartilaginous matirx, in vitro $[2,6,10$, 17]. Immunohistochemical studies of chick growth plates showed the localization of TGF- $\beta_{3}$ LAP in proliferative and early-stage hypertrophic chondrocytes, while its immunoreactivity decreased in later stages [20]. Therefore, the distribution of TGF- $\beta_{3}$-positive cells in this experimental model resembled that in the growth plates. In the present study, employing murine ligamenta flava, we could find evidence of the immunolocalization of neither TGF- $\beta_{1}$, nor $-\beta_{2}$ since their levels of reactivity were either too weak or lacked specificity. The previous report, regarding TGF- $\beta$-localizations in chick growth plates, also highlighted the weaker or more restricted immunoreactivities of TGF- $\beta_{1}$, and $-\beta_{2}$ compared with that of TGF$\beta_{3}$, suggesting a difference in distribution and intensity, among TGF- $\beta$ isoforms [20]. Moreover, TGF- $\beta_{2}$ appears to exert greater influence, with regard to the induction of osteogenesis and chondrogenesis, than other isoforms in rats [9], while in mice, TGF- $\beta_{3}$ is the more important at the early stage of differentiation in the process of endochondral ossification, as well as the active growth and differentiation of chondroblasts [16]. The different roles and effects among the TGF- $\beta$ isoforms in the various species or tissues may reflect certain discrepancies in immunolocalizations of the TGF- $\beta$ isoforms observed in the present study.

Proliferative or hypertrophic chondrocytes in the central portion were also immunopositive for the TGF- $\beta$ type I receptor. Receptors types I and II were both necessary for successful transduction of TGF- $\beta$ signaling [1, 3]. The immunolocalization of the type I receptor in these kinds of chondrocytes may suggest autocrine/paracrine system of
TGF- $\beta$. Therefore, in this experimental model, exogenous BMP-2 was thought to induce the chondrification of ligamentous fibroblasts and the subsequent TGF- $\beta$ synthesis by the chondrocytes. Moreover, both exogenous BMP-2 and endogenous TGF- $\beta$ may promote the matrix formation and the maturation of chondrocytes cooperatively. In clinica, TGF- $\beta$ would also stimulate the chondrocytic maturation which is primarily essential for ossification of spinal ligaments.

\section{Acknowledgments}

We would like to thank Yamanouchi Pharmaceutical Co., Ltd. for their kindly providing rhBMP-2. We express our sincere appreciation to Dr. Kohei Miyazono, Department of Biochemistry, The Cancer Institute located in Tokyo, Japan for their kindly supplying polyclonal rabbit antisera against TGF- $\beta_{1}$ LAP, $\beta_{2}$ LAP, $\beta_{3}$ LAP, the TGF- $\beta$ type I receptor. We also wish to thank Mr. Kendall J. T. Walls for his valuable assistance in the preparation of the manuscript.

This work was supported in part by Grants-in-Aid from the Ministry of Education, Science and Culture, Japan, to H. Ozawa (No. 08877269) and by a grant from Research Fellowships of the Japan Society for the Promotion of Science for Young Scientists to K. Hoshi (No. 1766).

\section{References}

1. Attisano, L., Carcamo, J., Ventura, F., Weis, F. M., Massague, J. and Wrana, J. L.: Identification of human activin and TGF $\beta$ type I receptors that form heteromeric kinase complexes with type II receptors. Cell 75; 671-680, 1993.

2. Ballock, R. T., Heydemann, A., Wakefield, L. M., Flanders, K. C., Roberts, A. B. and Sporn, M. B.: TGF- $\beta 1$ prevents hypertrophy of epiphyseal chondrocytes: regulation of gene expression for cartilage matrix proteins and metalloproteases. Dev. Biol. 158; 414-429, 1993.

3. Franzen, P., ten Dijke, P., Ichijo, H., Yamashita, H., Schulz, P., Heldin, C. and Miyazono, K.: Cloning of a TGF $\beta$ type I receptor that forms a heteromeric complex with the TGF $\beta$ type II receptor. Cell 75; 681-692, 1993.

4. Hattori, H., Kawai, M., Yasue, K., Mizutani, H., Kobayashi, M., Kaneda, T. and Hoshino, T.: A correlative immuno-light and electron microscopic study on the type I collagen in the bone morphogenetic protein-induced cartilage. J. Electron Microsc. 42; 400-406, 1993.

5. Henriksen, R., Gobl, A., Wilander, E., Oberg, K., Miyazono, K. and Funa, K.: Expression and prognostic significance of TGF- $\beta$ isotypes, latent TGF- $\beta 1$ binding protein, TGF- $\beta$ type I and type II receptors, and endoglin in normal ovary and ovarian neoplasms. Lab. Invest. 73; 213-220, 1995.

6. Hiraki, Y., Inoue, H., Hirai, R., Kato, Y. and Suzuki, F.: Effect of transforming growth factor beta on cell proliferation and glycosaminoglycan synthesis by rabbit growth-plate chondrocytes in culture. Biochim. Biophys. Acta 969; 91-99, 1988.

7. Horisaka, Y., Okamoto, Y., Matsumoto, N., Yoshgimura, Y., Hirano, A., Nishida, M., Kawada, J., Yamashita, K. and Takagi, T.: Histological changes of implanted collagen material during bone induction. J. Biomed. Mater. Res. 28; 
97-103, 1994.

8. Hoshi, K., Amizuka N., Sakou, T., Kurokawa, T. and Ozawa, H.: Fibroblasts of spinal ligaments pathologically differentiate into chondrocytes induced by recombinant human bone morphogenetic protein-2: morphological examinations for ossification of spinal ligaments. Bone 21; 155-162, 1997.

9. Joyce, M. E., Roberts, A. B., Sporn, M. B. and Bolander, M.E.: Transforming growth factor $\beta$ and the initiation of chondrogenesis and osteogenesis in the rat femur. J. Cell Biol. 110; 2195-2207, 1990.

10. Kato, Y., Iwamoto, M., Koike, T., Suzuki, F. and Takano, Y.: Terminal differentiation and calcification in rabbit chondrocyte cultures grown in centrifuge tubes: regulation by transforming growth factor $\beta$ and serum factors. Proc. Natl. Acad. Sci. USA. 85; 9552-9556, 1988.

11. Kawaguchi, H., Kurokawa, T., Hoshino, Y., Kawahara, H., Ogata, E. and Matsumoto, T.: Immunohistochemical demonstration of bone morphogenetic protein-2 and transforming growth factor- $\beta$ in the ossification of the posterior longitudinal ligament of the cervical spine. Spine 17; S33-S36, 1992.

12. Mizutani, H., Hattori, H., Yasue, K., Senga, K., Kawai, M., Ueda, M. and Hoshino, T.: The hypertrophic chondrocytes of the bone morphogenetic protein induced cartilage. Jpn. J. Oral Biol. 38; 309-316, 1996.

13. Noda, M. and Camilliere, J. J.: In vivo stimulation of bone formation by transforming growth factor- $\beta$. Endocrinology 124; 2991-2994, 1989.

14. Olofsson, A., Miyazono, K., Kanzaki, T., Colosetti, P., Engstrom, U. and Heldin, C. H.: Transforming growth factor$\beta 1,-\beta 2$, and $-\beta 3$ secreted by a human glioblastoma cell line. Identification of small and different forms of large latent complexes. J. Biol. Chem. 267; 19482-19488, 1992.
15. Raqib, R., Lindberg, A. A., Bjork, L., Bardharn, P. K., Wretlind, B., Anderson, U. and Andersson, J.: Down-regulation of gamma interferon, tumor necrosis factor type $I$, interleukin 1 (IL-1) type I, IL-3, IL-4, and transforming growth factor $\beta$ type I receptors at the local site during the acute phase of Shigella infection. Infect. Immun. 63; 3079-3087, 1995.

16. Schmid, P., Cox, D., Bilbe, G., Maier, R. and McMaster, G. K.: Differential expression of TGF $\beta 1, \beta 2$ and $\beta 3$ genes during mouse embryogenesis. Development 111; 117-130, 1991.

17. Seyedin, S. M., Thompson, A. Y., Bentz, H., Rosen, D. M., McPherson, J. M., Conti, A., Siegel, N. R., Galluppi, G. R. and Piez, K. A.: Cartilage-inducing factor-A. Apparent identity to transforming growth factor-beta. J. Biol. Chem. 261; 5693-5695, 1986.

18. Taketazu, F., Kato, M., Gobl, A., Ichijo, H., ten Dijke, P., Itoh, J., Kyogoku, M., Ronnelid, J., Miyazono, K., Heldin, C. and Funa, K.: Enhanced expression of transforming growth factor- $\beta s$ and transforming growth factor- $\beta$ type II receptor in the synovial tissues of patients with rheumatoid arthritis. Lab. Invest. 70; 620-630, 1994

19. Tanaka, T., Taniguchi, Y., Gotoh, K., Satoh, R., Inazu, M. and Ozawa, H.: Morphological study of recombinant human transforming growth factor beta 1-induced intramembranous ossification in neonatal rat parietal bone. Bone 14; 117-123, 1993.

20. Thorp, B. H., Anderson, I. and Jakowlew, S. B.: Transforming growth factor- $\beta 1,-\beta 2$ and $-\beta 3$ in cartilage and bone cells during endochondral ossification in the chick. Development 114; 907-911, 1992.

21. Yamada, M.: Ultrastructural and cytochemical studies on the calcification of the tendon-bone joint. Arch. Histol. Jpn. 39; 347-378, 1976. 